\title{
The training contents, problems and needs of doctors in urban community health service institutions in China
}

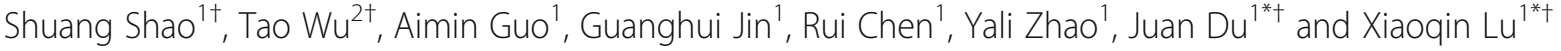

\begin{abstract}
Background: The Chinese government offered various types of training programs for strengthening the role of doctors working in community health service institutions (CHSIs). The study intended to investigate the current training programs and training needs of doctors nationally in urban CHSIs in China, and to provide propositions for training more qualified doctors in the future.

Methods: Total 3098 doctors in 192 urban CHSIs were chosen from 9 provinces (Hebei, Liaoning, Shandong, Zhejiang, Fujian, Hunan, Guangxi, Guizhou, Ningxia) and one municipality (Beijing) among 31 provinces in eastern, central, and western regions by stratified sampling methods in Mainland China. All doctors in the selected CHSIs were investigated in this study. We discharged 3073 questionnaires, and the response rate was 98.0\%. Descriptive statistics were used to describe the characteristics, training contents, problems and needs of doctors. Differences in training contents, problems and needs between eastern, central and western regions were analyzed with chi-square tests.
\end{abstract}

Results: $49.3 \%$ of doctors in CHSIs had Bachelor's degree and beyond. 12.9\% of doctors had senior professional titles. The most frequent training topics for the doctors in eastern, central and western regions were "basic clinical theory knowledge" (52.4\%), "community health service competency" (59.6\%), "clinical practice skills" (45.9\%) respectively. The most serious problem for doctors was "insufficient training time" in eastern (36.8\%), central (36.5\%) and western (39.6\%). The biggest knowledge need for doctors both in eastern (79.8\%) and central region (79.1\%) was "the updated international medical knowledge", in western region it was "the updated domestic medical knowledge" (73.2\%). The biggest skill-related training need for doctors in eastern region (84.1\%) and central region (82.6\%) was "communication skills", and "diagnosis and differential diagnosis" in western region (78.2\%).

Conclusion: Government should design proper training contents according to the knowledge and skill needs of different design. Furthermore, a uniform, rigorous training and evaluation system focus on practicability should be established to promote community health service system in Mainland China.

Keywords: Urban community health care service institutions, Doctors, Training programs, Training needs

\section{Background}

General practitioners (GPs, also called family physicians) are the first contact for patients within the health care system, providing preventive and medical services, referral to specialist and acute care when necessary, and playing a key role in community health service in China. There

\footnotetext{
*Correspondence: cuckoo@ccmu.edu.cn; xq6518@163.com

†Shuang Shao, Tao Wu, Juan Du and Xiaoqin Lu contributed equally to this work.

${ }^{1}$ School of General Practice and Continuing Education, Capital Medical University, Beijing 100069, China

Full list of author information is available at the end of the article
}

were 109,794 GPs which accounted for $5.6 \%$ of all registered physicians in 2012, and the number was far from the government's goal of 300,000 GPs by 2020 [1,2]. The goal is to reach the ratio of at least two or three GPs per 10,000 citizens by 2020 , however, the current ratio is 1.07 [3]. The total number of outpatient visits increased from 2010 to 2013 at all health care facilities, and the outpatient rate of hospital increased by $34.4 \%$, while the outpatient rate of community health service institutions (CHSIs) increased by only $19.7 \%$ [2]. The data concealed the fact that CHSIs were unable to attract a greater number of patients.

(c) The Author(s). 2018 Open Access This article is distributed under the terms of the Creative Commons Attribution 4.0 International License (http://creativecommons.org/licenses/by/4.0/), which permits unrestricted use, distribution, and reproduction in any medium, provided you give appropriate credit to the original author(s) and the source, provide a link to the Creative Commons license, and indicate if changes were made. The Creative Commons Public Domain Dedication waiver (http://creativecommons.org/publicdomain/zero/1.0/) applies to the data made available in this article, unless otherwise stated. 
Because of the lack of confidence in medical skills and the limited supply of advanced equipment and instruments in CHSIs, patients are not motivated to actively seek care in CHSIs for further treatments [4-7]. Thus, new and innovative initiatives are urgently in need to increase the quantity and quality of doctors to improve primary health care services.

Up to now, the Chinese government has proposed various approaches to reorganize hospital care and has put much emphasis on developing CHSIs. Since 2009, approximately $30 \%$ of government funds were invested in enhancing supply-side public infrastructure and training primary health care providers [8]. Furthermore, since 2000, the Chinese government offered various types of training programs for strengthening the role of all CHSIs providers, particularly for doctors (including GPs and physicians of other medical specialty who will be trained to be qualified GPs). The Chinese government has sought curriculum assistance from the World Organization of Family Doctors (WONCA) to improve the Chinese education, training and practice system. The education and training programs comprised undergraduate education, on-the-job training program or job-transfer training program, postgraduate residency training program, and continuing medical education (CME) programs. In most of medical schools in China, the "introduction to general practice" curriculum which is within 36 credit hours comprises of lecture sessions and practice sessions during the 5 years of undergraduate education: (1) the lecture sessions was designed to learn basic theories and concepts of general practice for students, including whole person care and holistic model; (2) the practice sessions was designed to acquire the preliminary impression of CHSIs for students. Currently, the job-transfer training program (replaced on-the-job training program from 2010) and the postgraduate residency training program (officially initiated from 2011) are the main two GPs training programs. On-the-job training program and transfer-job training program which offer a transitional solution for the shortage of GPs have a 1-year (full-time) training duration and target at retraining less trained CHSIs doctors who received 3 to 5 years of medical education after high school or other medical specialties to become a qualified GP. The programs were designed to promote clinical practical skills and theoretical knowledge through three phases: (1) academic curriculum, (2) Hospital-based clinical rotation, and (3) CHSIs-based training [9]. The postgraduate residency training program which lasts for 33 months (full-time) is mainly for graduates with 5 to 8 years post-high school medical education background, and includes two stages: (1) Hospital-based Clinical rotation and (2) CHSIs-based training [10]. Meanwhile, there are also other training programs as complements to training qualified GPs [11]. As CME programs (part-time), the train-the-trainer program, which emphasizes the training of qualified trainers, and the training programs hold by CHSIs, were considered supplements to teaching and training programs. Although there are various training programs, lack of knowledge on adequacy of contents, strengths, weaknesses of current training and future needs in China. Therefore, it is necessary to investigate the current training and future training needs of GPs nationally in china, however, no such study has been carried out to date.

\section{Methods \\ Ethics statement}

The research methods were performed in accordance with approved guidelines. Data were obtained from a 2011 cross-sectional survey, the Nationwide Investigation on Health Professionals of Community Health Service Institutions in Urban China. The study was undertaken as a part of a program sponsored by the Department of Medical Science, Technology and Education in China's Ministry of Health (renamed National Health and Family Planning Commission of the People's Republic of China in 2013, National Health Commission of the People's Republic of China in 2017). Written informed consent was obtained from each participating doctors in this study.

\section{Sampling methods and participants}

The general stratified sampling method was adopted to select 9 provinces and one municipality from the available 31 provinces (including five autonomous regions and four municipalities) which divided into three regions (eastern region, central region and western region) in Mainland China;then the provincial capital cities and two other random cities (from above and below the median GD) were selected from each province; then 3 city districts based on good, moderate and poor economic condition were selected from each city; finally, 3 CHSIs were selected according to the CHSIs' development status (good, moderate or poor). In summary, 9 provinces and one municipality, 28 cities, 66 districts and 192 $\mathrm{CHCs}$ were selected for the survey. (the sampling flow was described in Fig. 1) We investigated all doctors who were regular employees at 192 CHSIs, rehired retirees and temporary employees were excluded. Overall, 3098 eligible doctors in the selected CHSIs were sent questionnaires to complete and return.

\section{Data collection and quality control}

The investigation studied the training status and needs of doctors in Chinese urban CHSIs. Fieldwork was performed from May to November 2011. The quality assurance measures for this investigation included evaluating the questionnaire, training the investigators, and asking a fieldwork supervisor to monitor the investigation 


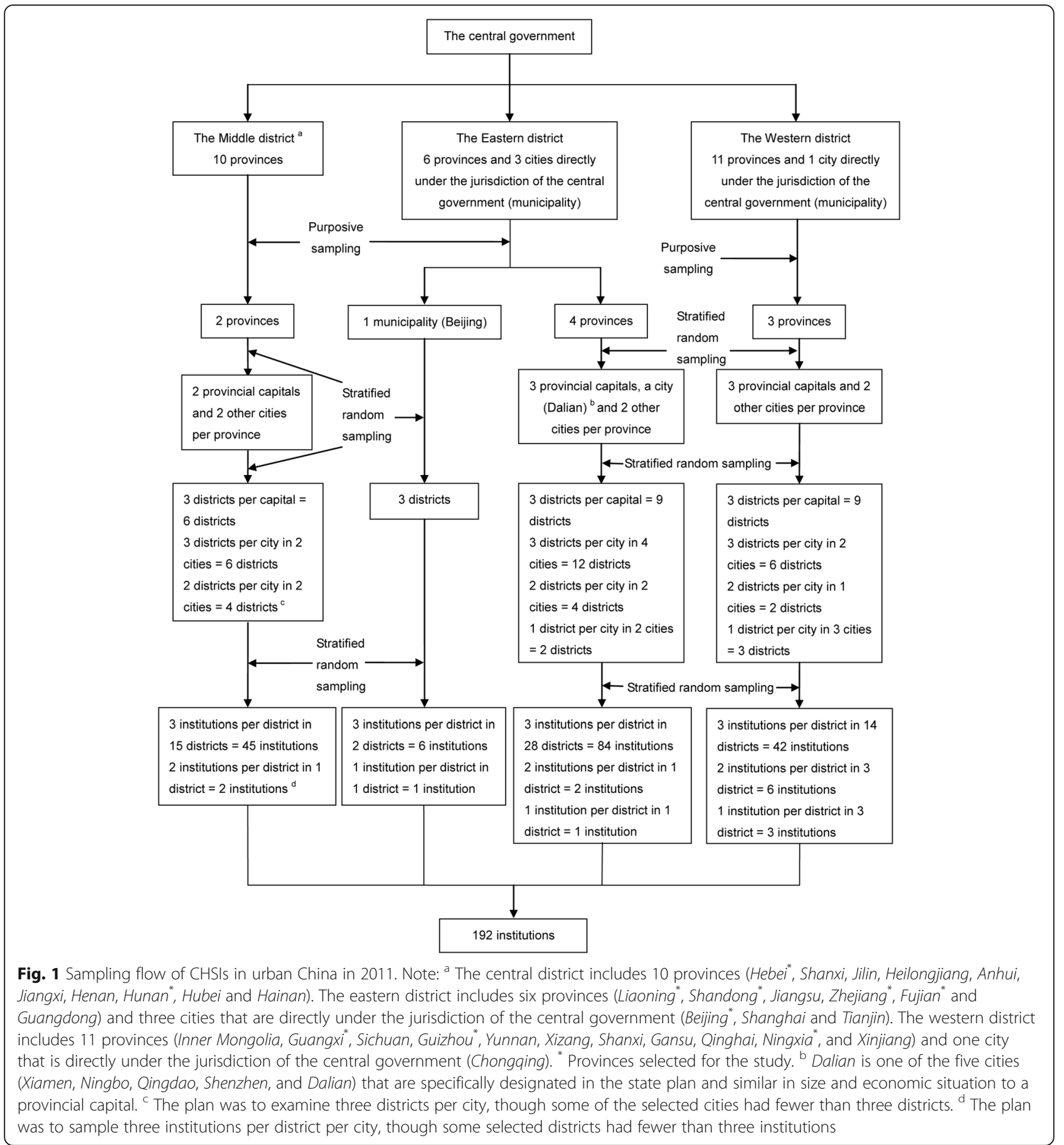

process. Before the investigation was implemented, it was reviewed, edited, and validated by 29 experts from health administrative department, clinical teaching hospital and CHSIs. The questionnaire (see Additional file 1) consists of three parts of contents as following: characteristic of health providers (e.g. socio-demographic, workplace, educational and title level), training status (e.g. the types of training programs, training contents, and training problems), and training needs (e.g. the attitude to training, training motivation, the knowledge and skills needs of training, etc). Collective training for 126 coordinators from investigated provinces was held in Beijing on May 2, 2011 by Technology and Education of China's Ministry of Health and our research group. They implemented the ensuing training for investigators at community-level in the next stage. Three hundred and eighty four administrative leaders of the CHSIs and fieldwork supervisor were responsible for monitoring 
the process. They checked the completed questionnaires to avoid missing data. A pilot survey of 100 participants was conducted between May 6 and May 10, 2011, in Beijing to assess the feasibility of the questionnaire and the fieldwork procedures. The questionnaires and data were validated by our research experts. All data adopted double entry by using EpiData software (Version 3.1, EpiData association, Odense, Denmark). The two databases were compared and analyzed for discrepancies. If discrepancies exist, the original data source would be reviewed. To avoid wrong information disturbing the research results, logical contradiction and missing data of items in the questionnaires which we will analysis in the manuscript were confirmed via telephone to correct and supplement information.

\section{Statistical analysis}

All analyzes were conducted by using the Statistical Package for Social Sciences (SPSS) for Windows (Version 17.0; SPSS, Inc., Chicago, IL, USA) Descriptive statistics (frequencies and percentages) were used to describe the characteristics of doctors status and needs of training. Differences of training contents, problems and needs between eastern, central and western regions were tested with chi-square tests. The tests was two-sided, and $P<0.05$ was considered statistically significant.

\section{Results}

\section{Characteristics of doctors}

A total of 3037 (out of 3098) doctors consented to participate in this study and the remaining 61 declined, and the response rate was $98.0 \%$. Table 1 shows the social demography characteristic of participants in three regions. In all, 39\% were male and $61 \%$ were female. There was significant difference in education level $(P<0.001)$ and title level $(P<0.001)$ of doctors among three regions. In three regions, the doctors of western region had the highest education level. Both doctors of the central region had the lowest education level in three regions. In three regions, more doctors of western region $(119,16.2 \%)$ had the senior title level than eastern region $(214,12.1 \%)$ and central region $(59,10.9 \%)$, while doctors of central region had the lowest title level.

Figure 2 shows that the top five categories of physicians' registration reported were internal medicine (872, 28.7\%), GP (690, 22.7\%), surgery (329, 10.8\%), gynecology and obstetrics $(254,8.4 \%)$ and pediatrics $(176,5.8 \%)$.

\section{Training status}

Figure 3 indicates that $89.2 \%$ (2709) doctors had attended at least one type of training program. 1361 $(44.8 \%)$ and $333(11.0 \%)$ had attended on-the-job training and job-transfer training programs respectively. 612 (20.2\%) had attended the train-the-trainer program.

Table 1 Distribution of total participants by the social demography characteristics in three regions

\begin{tabular}{|c|c|c|c|c|c|}
\hline & \multicolumn{4}{|c|}{ Doctors (NO.\%) } & \multirow[t]{2}{*}{$P$} \\
\hline & Eastern & Central & Western & Total & \\
\hline CHSIs Number & $94(48.9)$ & $47(24.5)$ & $51(26.6)$ & $192(100)$ & \\
\hline Gender & & & & & 0.195 \\
\hline Male & 684(38.8) & 212(39.3) & 288(39.2) & 1184(39.0) & \\
\hline Female & 1078(61.2) & $328(60.7)$ & $447(60.8)$ & 1854(61.0) & \\
\hline Education level* & & & & & $<0.001$ \\
\hline Undergraduate and above & $837(47.5)$ & 229(42.4) & $434(59.0)$ & $1500(49.3)$ & \\
\hline Junior college & 593(33.7) & 236(43.7) & $196(26.7)$ & 1025(33.8) & \\
\hline Technical secondary school/ High school & $313(17.8)$ & $73(13.5)$ & 105(14.3) & $491(16.2)$ & \\
\hline Below high school & 19(1.1) & $2(0.4)$ & $0(0.0)$ & $21(0.7)$ & \\
\hline Title level\# & & & & & $<0.001$ \\
\hline Senior title & $214(12.1)$ & $59(10.9)$ & 119(16.2) & $392(12.9)$ & \\
\hline Middle title & $657(37.3)$ & $152(28.1)$ & $277(37.7)$ & 1086(35.8) & \\
\hline Junior title and below & $786(44.6)$ & $275(50.9)$ & 291(39.6) & $1352(44.5)$ & \\
\hline No title & $105(6.0)$ & $54(10.0)$ & $48(6.5)$ & 207(6.8) & \\
\hline
\end{tabular}

Note: $\mathrm{SD}=$ standard deviation

* In China, medical educational programs include 5- to 8-year post-high school training programs, 3-year post-high school programs which are decreasing, 4-year post-middle school programs which have almost disappeared, and barefoot doctors (who are basically farmers with no proper medical education, usually only 3 to 6 months of basic medical training, and take care of the primary health care needs in their communes)

\# Senior title (assistant chief physician or chief physician)

Middle title (attending physician)

Junior title and below (resident physician or assistant doctor) 


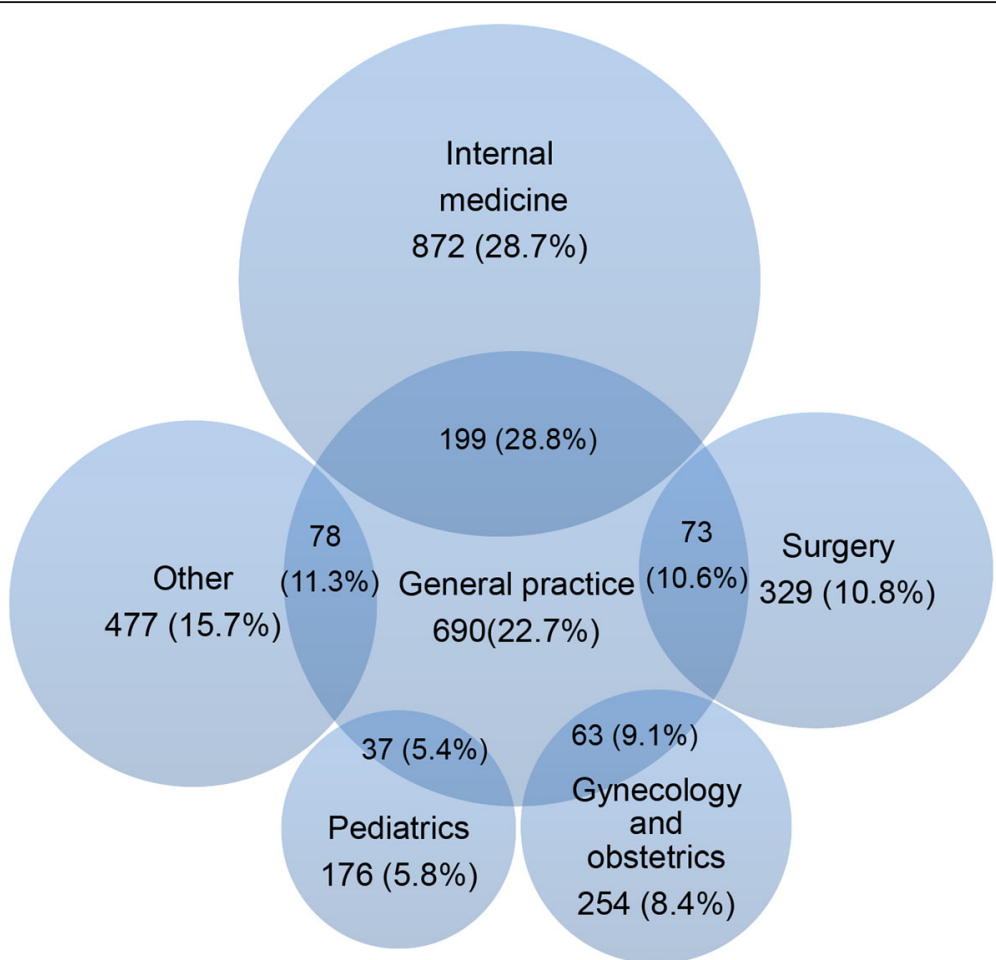

Fig. 2 The proportion of doctors registered in physician practice scope of clinical categories. Note: The Chinese government has ruled that doctors in primary health care institutions can register no more than three different specialties in one category. Source: National Health and Family Planning Commission of the People's Republic of China. The notice of interim provisions on physicians practicing registered scope issued by Ministry of Health. Available from: http://www.gov.cn/gongbao/content/2002/content_61429.htm

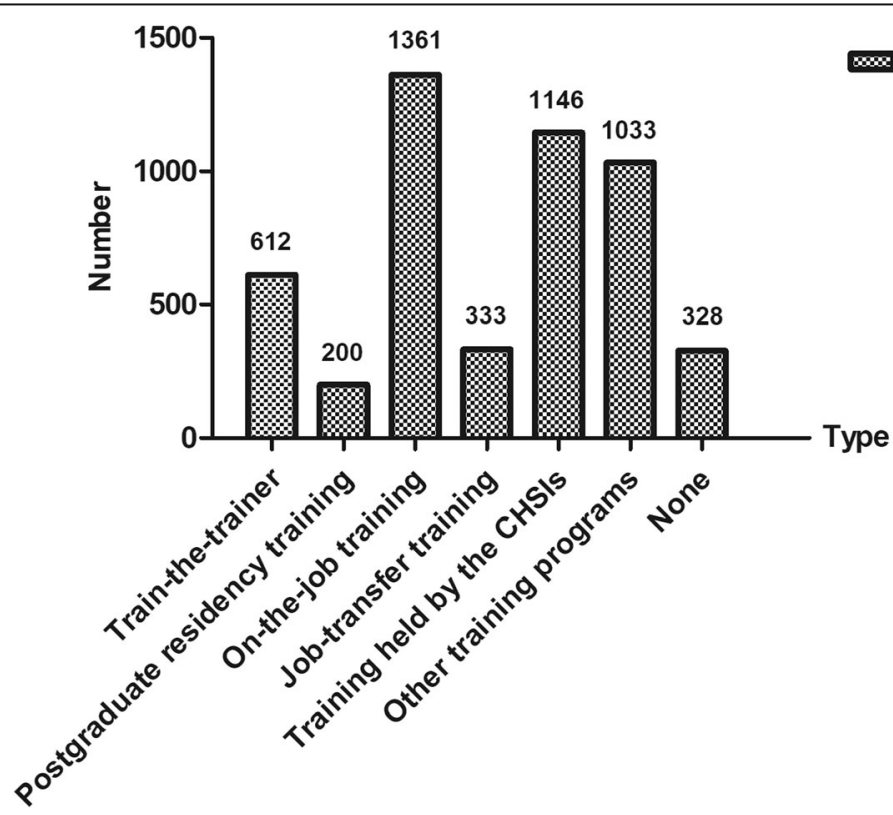

Fig. 3 The types of training programs attended by the CHSIs doctors. Note: Doctors may attend more than one type of training, and some values overlapped 
Only 200 (6.9\%) doctors had attended postgraduate residency training program. Table 2 indicates the differences between a series of training programs for GPs in China.

Table 3 shows the types of training programs attended by the CHSIs doctors in three regions. Compared with central and eastern regions, fewer doctors in western region had received on-the-job training. The doctors of central region had lowest ratio in participating postgraduate residency training.

Table 4 describes the topics and problems in the training programs reported by doctors in CHSIs in three regions. Comparing with eastern and central regions, the doctors of western region received least training in "community health service competency" and "clinical practice skills". The biggest problem in the training programs for doctors in all three regions was "insufficient training time".

\section{Training needs}

Most of the doctors (95.0\%) were willing to attend training programs regularly. Table 4 also describes the top five knowledge and skill training needs of doctors. The doctors of eastern and central regions had more knowledge needs of "the updated domestic medical knowledge" and "The updated international medical knowledge" than western region. Comparing to the western region, doctors of the eastern and central regions had more skill training needs of "communication skills", "physical examination", "observation skills" and "clinical medication use".

\section{Discussion}

The recent House of Commons Health Select Committee report on the workforce argued that "the quality, safety, effectiveness and efficiency of health care services depend on the availability of sufficient numbers of well-trained and well-motivated staff" [12]. At present, there are many challenges facing general practice, including rising patient and physician expectations, growing comprehensive and continuous of care, burgeoning technique, and expanding knowledge base [13]. Thus, it is necessary to increase more well-trained GPs to play the role of gate-keeper in CHSIs of China. In our study, the participants have high willingness to receive training. Furthermore, 89.2\% doctors had attended at least one type of training program, including on-the-job training, job-transfer, and other CME programs, etc.

From the international perspective, the scopes and contents of training programs need to be designed and broadened to meet the knowledge and skill needs for doctors. There is a trend toward competency-based rather than time-based training, with the trainees expected to demonstrate certain competencies to enhance the level of training $[14,15]$. Six core competencies relevant to any modern domain of medical practice should be emphasized on training programs, including patient care, medical knowledge, communication skills, professionalism, practice-based learning and improvement, and system-based practice [16]. At present, the training contents for GPs concentrate on customized contents of doctor-patients communication skills, community-based healthcare competency, clinical skills and knowledge [17-19]. Such as the "Practice Support Program of Canada", topic areas range from clinical tools/skills to office management, and the five learning modules consist of advanced access, chronic disease management, patient self management, group medical visits, and adult mental health were trained in three half-day learning sessions and 6-8 week practice periods [20]. Compared with the training contents of other country, our findings demonstrated that

Table 2 The differences between a series of training programs for GPs in China

\begin{tabular}{|c|c|c|c|c|}
\hline Differences & $\begin{array}{l}\text { Postgraduate residence } \\
\text { training program }\end{array}$ & $\begin{array}{l}\text { On-the-job training } \\
\text { program/job-transfer } \\
\text { training program }\end{array}$ & $\begin{array}{l}\text { Train-the-trainer } \\
\text { training program }\end{array}$ & $\begin{array}{l}\text { Training program } \\
\text { held by CHSls }\end{array}$ \\
\hline Target population & $\begin{array}{l}\text { Graduates whose medical background } \\
\text { is } 5 \text { - to 8-year post-high school } \\
\text { education or over, and who are } \\
\text { likely to choose general practice } \\
\text { as a career. }\end{array}$ & $\begin{array}{l}\text { Community health physicians } \\
\text { with 3- to 5-year post-high } \\
\text { school medical education, } \\
\text { who are willing to become } \\
\text { general practitioners by } \\
\text { on-the-job training. }\end{array}$ & $\begin{array}{l}\text { Clinical faculty from } \\
\text { hospital, clinical faculty } \\
\text { from CHSIs and } \\
\text { theoretical faculty } \\
\text { from university }\end{array}$ & $\begin{array}{l}\text { Doctors working } \\
\text { in CHSIs. }\end{array}$ \\
\hline $\begin{array}{l}\text { Teaching contents/ } \\
\text { curriculum }\end{array}$ & $\begin{array}{l}\text { (1) Hospital-based Clinical rotation; } \\
\text { (2) CHSIs-based training. }\end{array}$ & $\begin{array}{l}\text { (1) Academic curriculum; } \\
\text { (2) Hospital-based clinical } \\
\text { rotation; } \\
\text { (3) CHSIs-based training. }\end{array}$ & $\begin{array}{l}\text { (1) Task responsibilities } \\
\text { and contents } \\
\text { for GP faculty; } \\
\text { (2) Clinical teaching } \\
\text { contents and methods; } \\
\text { (3) Theoretical knowledge } \\
\text { and clinical skill; }\end{array}$ & $\begin{array}{l}\text { Basic medical services, } \\
\text { chronic management, } \\
\text { preventive care, etc. }\end{array}$ \\
\hline Training lengths & 33 months (full-time) & 12 months (full-time) & 2 months & Irregularly scheduled \\
\hline $\begin{array}{l}\text { Type of certificates } \\
\text { obtained }\end{array}$ & $\begin{array}{l}\text { Standardized residency training } \\
\text { certificate which is issued by } \\
\text { Ministry of Health and is a prerequisite } \\
\text { for the qualification of GP. }\end{array}$ & $\begin{array}{l}\text { GP on-the-job training } \\
\text { certificate which is } \\
\text { issued by provincial } \\
\text { health department. }\end{array}$ & $\begin{array}{l}\text { GP faculty training } \\
\text { certificate which is } \\
\text { issued by provincial } \\
\text { health department. }\end{array}$ & None \\
\hline
\end{tabular}


Table 3 The types of training programs attended by doctors in CHSIs in three regions

\begin{tabular}{llllll}
\hline Type of training program & \multicolumn{3}{l}{ Doctor (NO.\%) } & $P$ \\
\cline { 2 - 4 } & Eastern & Central & Western & \\
\hline On-the-job training & $869(49.3)$ & $232(43.0)$ & $260(35.4)$ & $<0.001$ \\
Postgraduate residency training & $137(7.8)$ & $13(2.4)$ & $50(6.8)$ & $<0.001$ \\
Job-transfer training & $170(9.7)$ & $56(15.9)$ & $77(10.5)$ & $<0.001$ \\
Train-the-trainer & $361(20.5)$ & $118(21.9)$ & $133(18.1)$ & 0.349 \\
Training held by the CHSIs & $776(44.0)$ & $161(29.8)$ & $209(28.4)$ & $<0.001$ \\
\hline
\end{tabular}

Note: Doctors may attend more than one type of training, and some values overlapped

the training contents in three regions, were similar with the competency-based training contents. Nevertheless, we also found some key problems, including insufficient training time, deficiency in clinical practice skills, and lack of practical training contents. Actually, limited understanding of the clinical decision-making processes and difficulty in translating knowledge to practice become common phenomenon [21]. So it is necessary to highlight training contents with strong practicability in training programs at present and in the future. It is also suggested that teaching hospitals should train GPs to grasp the basic skills such as the film reading of X-ray, CT, MRI and ECG, emergency treatment, and physical examination in clinical rotations [5]. Insufficient training time is a worldwide problem, which has been attributed to increasing workloads and far distance from training place [22]. For doctors, flexibility of training time is recommended as an effective method to resolve the contradiction between work and training, so training in CHSIs themselves would attract more trainees. The work-hour constraints requires training model to find the proper balance between continuity of care and the trainee fatigue. Worldwide, many configurations and approaches can compensate for this obstacle, including videoconferencing, distance learning, and web based learning [23-25]. It is worth mentioning that the "communication skills" was the most important skill for doctors in this study. The role of patients' support and gratitude could reduce health care providers' burnout [26]. Professionalism and interpersonal communication skills have been incorporated formally into medical training recently. Knowing when, what, and how to communicate with patients can be seen as an essential part of skills training. Teaching hand in hand, [27] providing a "toolkit" of skill, [28] and personal reflection [27] could be applied to overcome the problems in communication skill training.

Table 4 The training contents, problems and needs of doctors in CHSIs in three regions

\begin{tabular}{|c|c|c|c|c|}
\hline & \multicolumn{3}{|c|}{ Doctor (NO.\%) } & \multirow[t]{2}{*}{$P$} \\
\hline & Eastern & Central & Western & \\
\hline \multicolumn{5}{|l|}{ Training topics } \\
\hline Basic clinical theory knowledge & $880(52.4)$ & $272(50.4)$ & $333(45.3)$ & 0.081 \\
\hline Clinical practice skills & $898(51.0)$ & $282(52.2)$ & $337(45.9)$ & 0.034 \\
\hline Community health service competency & $908(51.5)$ & $322(59.6)$ & $314(42.7)$ & $<0.001$ \\
\hline Preventive care & $364(20.7)$ & 128(23.7) & 145(19.7) & 0.200 \\
\hline \multicolumn{5}{|l|}{ Training problems } \\
\hline An excessively short training time & 649(36.8) & 197(36.5) & 291(39.6) & 0.379 \\
\hline Insufficient training content & $575(32.6)$ & 181(33.5) & 219(29.8) & 0.284 \\
\hline Deficiency in clinical practice skills & $451(25.6)$ & 156(28.9) & 182(24.8) & 0.215 \\
\hline Insufficient resolution of problems at work & $465(26.4)$ & 143(26.5) & 182(24.8) & 0.674 \\
\hline \multicolumn{5}{|l|}{ Knowledge needs } \\
\hline The updated international medical knowledge & 1406(79.8) & $427(79.1)$ & $532(72.4)$ & 0.066 \\
\hline The updated domestic medical knowledge & 1357(77.0) & $422(78.1)$ & $538(73.2)$ & $<0.001$ \\
\hline Clinical experience & $549(31.2)$ & 201(37.2) & 206(28.0) & 0.002 \\
\hline Clinical decision making & $488(27.7)$ & 164(30.4) & 183(24.9) & 0.092 \\
\hline Clinical medication & $462(26.2)$ & 162(30.0) & 195(26.5) & 0.213 \\
\hline \multicolumn{5}{|l|}{ Skill needs } \\
\hline Communication skills & $1481(84.1)$ & $446(82.6)$ & $569(77.4)$ & $<0.001$ \\
\hline Diagnosis and differential diagnosis & $1446(82.1)$ & $442(81.9)$ & $575(78.2)$ & 0.074 \\
\hline Physical examination & 1385(77.1) & $407(75.4)$ & $509(69.3)$ & $<0.001$ \\
\hline Observation skills & 1335(75.8) & $406(75.2)$ & $519(70.6)$ & 0.024 \\
\hline Clinical medication use & $1317(74.7)$ & $401(74.3)$ & $502(68.3)$ & 0.003 \\
\hline
\end{tabular}


In general, doctors in three regions had similar training courses, problems and needs. While, doctors of western region receive least contents related to "community health service competency", and had least knowledge and skill needs than other two regions. Comparing with the advantage of economic development for eastern region, the central and western regions have financial and medical care policy support provided by central government to develop community health services and general practice training, especially in western region [29]. In Ningxia, most of the CHSIs were transformed from secondary or tertiary hospitals, while CHSIs in other districts were independently regulatory institutions, thus health care providers especially doctors needed to meet more restrict criteria to enter the hospitals. In the future, "community health service competency" including chronic disease management, preventive care should be considered as the important parts of training in western regions.

\section{Strengths and limitations}

The strengths of this study are that it has brought questionnaire investigation on the current training programs and training needs of doctors in CHSIs in nationally. We carried out a series of quality control measures by a multidisciplinary team to ensure a depth of understanding critical to the design of the study and the validity of results. However, several limitations need to be considered: (1) although the study selected different CHSIs from the eastern, central and western regions to decrease the likelihood of bias, the use of purposive sampling restricted the generalizability of results because more of the relatively developed districts in the central and western regions were investigated. (2) although there were no sensitive topics, and each participant wrote informed consent, it is undeniable that participants which were not anonymised to answer the questionnaires will reduce the authenticity of research to some extent; (3) we mainly investigated the subjective opinions of the participants rather than objective indicators. Thus, the evaluation that focuses on structure and process should be implemented to discover the problems of training programs. In further research, the study will focus on the periodic evaluation of their knowledge and competency in career; (4) although the research took place in 2011, until now, there was no similar nationwide survey conducted in China. In recent years, the Chinese government has gradually realized the importance of primary care and issued some relevant policies and regulations. In 2018, the Chinese government proposed a comprehensive reform to improve the training of GPs, and some measures will be taken to promote the training programs. The results of our study could provide propositions for training more qualified GPs in the future.

\section{Conclusions}

China is suffering from a severe shortage of qualified GPs. Under the work-hour restriction circumstance, government should learn the advanced international education and training models to improve the effectiveness of training programs. Moreover, the government should design proper training contents according to the knowledge and skill needs of the different regions. Furthermore, a uniform, rigorous training and evaluation system focus on practicability should be established to promote community health service system in Mainland China.

\section{Additional file}

Additional file 1: An questionnaire investigation of training status and needs for doctors working in community health service institutions in China. Note: The questionnaire was designed to collect some information about the training status and needs for doctors working in community health service institutions in China. (DOC 58 kb)

\section{Abbreviations}

CHSIs: Community health service institutions; CME: Continuing medical education; GPs: General practitioners; SPSS: Statistical Package for Social Sciences; WONCA: World Organization of Family Doctors

\section{Acknowledgments}

We wish to thank Xiaoping Liu for helping coordinate the fieldwork and Shaojie Liu and Shengguo Jin for their help in organizing the investigation. We also would like to thank all of the research participants for their support and help to our research.

\section{Funding}

The study was undertaken as a part of a program sponsored by the Department of Medical Science, Technology and Education in China's Ministry of Health (renamed National Health and Family Planning Commission of the People's Republic of China in 2013).

Availability of data and materials

The datasets generated and/or analyzed during the current study are available from the corresponding author on reasonable request.

Authors' contributions

AMG, XQL and JD conceived and designed the experiments. TW, RC, YLZ and SS performed the experiments. SS and GHJ analyzed the data. SS, XQL and JD wrote the paper. All authors read and approved the final manuscript.

Ethics approval and consent to participate

It was approved by the Ethical Committee of Capital Medical University, Beijing, China. Data were obtained from a 2011 cross-sectional survey, the Nationwide Investigation on Health Professionals of Community Health Service Institutions in Urban China. Written informed consent was obtained from each participant involved in this study.

Consent for publication

Not applicable.

Competing interests

The authors declare that they have no competing interests.

\section{Publisher's Note}

Springer Nature remains neutral with regard to jurisdictional claims in published maps and institutional affiliations. 


\section{Author details}

${ }^{1}$ School of General Practice and Continuing Education, Capital Medical University, Beijing 100069, China. ${ }^{2}$ Department of Scientific Research, Beijing Anzhen Hospital, Capital Medical University, Beijing 100029, China.

Received: 12 June 2018 Accepted: 13 November 2018

Published online: 28 November 2018

\section{References}

1. National Health and Family Planning Commission of the People's Republic of China. China health statistical yearbook 2013 [in Chinese]; 2013. Available from: http://www.nhfpc.gov.cn/htmlfiles/zwgkzt/ptjnj/year2013/index2013. html. Accessed 26 Apr 2014.

2. National Health and Family Planning Commission of the People's Republic of China [Internet]. The notice of medicine and health care medium-term and long-term talents development plan (2011-2020) issued by Ministry of Health [in Chinese]; 2011. Available from: http://www.nhfpc.gov.cn/renshi/s3573/ 201104/ff5e914696cb461f9b8353a463198f54.shtml. Accessed 28 Apr 2011.

3. Yip WC, Hsiao WC, Meng QY, Chen W, Sun XM. Realignment of incentives for health-care providers in China. Lancet. 2010;375:1120-30.

4. Syed MA, Hossain MA, RajaChowdhury AM, Bhuiya AU. The health workforce crisis in Bangladesh: shortage, inappropriate skill-mix and inequitable distribution. Hum Resour Health. 2011;9:3.

5. Zhao YL, Chen R, Wang B, Wu T, Huang YF, Guo AM. General practice onthe-job training in Chinese urban community: a qualitative study on needs and challenges. PLoS One. 2014;9(4):e94301.

6. Ministry of Health and National Administration of Chinese Traditional Medicine [Internet]. Basic standards of urban community health service center and station [in Chinese]; 2006. Available from: http://www.gov.cn/ zwgk/2006-08/10/content_359200.htm. Accessed 10 Aug 2006.

7. Jin GH, Zhao YL, Chen C, Wang WJ, Du J, Lu XQ. The length and content of general practice consultation in two urban districts of Beijing: a preliminary observation study. PLoS One. 2015;10(8):e0135121.

8. Yip WC, Hsiao WC, Chen W, Hu S, Ma J, Maynard A. Early appraisal of China's huge and complex health-care reforms. Lancet. 2012;379:833-42.

9. The Central People's Government of the People's Republic of China. State Council's Opinion on establishing the general practitioners system [in Chinese]; 2011. Available: http://www.gov.cn/zwgk/2011-07/07/content_ 1901099.htm. Accessed 7 July 2011.

10. National Health and Family Planning Commission of the People's Republic of China[Internet]. The notice of print and distribute the GPs standard cultivation standard (trial) [in Chinese]; 2012. Available from: http://www. nhfpc.gov.cn/zwgkzt/pkjjy1/201207/55508.shtml. Accessed 30 July 2012.

11. The Central People's Government of the People's Republic of China [Internet]. The construction of primary care workforces is focused on general practitioners [in Chinese]; 2010. Available from: http:/www.gov.cn/ gzdt/2010-04/01/content_1571324.htm. Accessed 4 Oct 2010.

12. Binder LF, Rudolph B. Commentary: a systematic review of health care efficiency measures. Health Serv Res. 2009;44:806-11.

13. Roberts RG, Hunt VR, Kulie TI, et al. Family medicine training-the international experience. Med J Aust. 2011;194(11):S84-7.

14. Kiguli-Malwadde E, Olapade-Olaopa EO, Kiguli S, et al. Competency-based medical education in two Sub-Saharan African medical schools. Adv Med Educ Pract. 2014:5:483-9.

15. Caccia N, Nakajima A, Kent N. Competency-based medical education: the wave of the future. J Obstet Gynaecol Can. 2015;37(4):349-53.

16. Round WH. Continuing professional development systems for medical physicists: a global survey and analysis. Phys Med. 2013;29(3):261-72.

17. Stevenson DG, Huskamp HA. Integrating care at the end of life: should medicare advantage include hospice? JAMA. 2014;311:1493-4.

18. Thistlethwaite JE, Kidd MR, Hudson JN. General practice: a leading provider of medical student education in the 21st century? MJA. 2007;187:124-8.

19. Thaver AM, Sobani ZA, Qazi F, Khan M, Asim Beg AZM. Assessing the need for training: general practitioners' knowledge, attitude and practice concerning dengue and malaria in Karachi, Pakistan. Int Health. 2011;3:126-30

20. MacCarthy D, Kallstrom L, Kadlec H, Hollander M. Improving primary care in British Columbia, Canada: evaluation of a peer-to-peer continuing education program for family physicians. BMC Med Educ. 2012;12:110.

21. Ten Cate O, Hart D, Ankel F, et al. Entrustment decision making in clinical training. Acad Med. 2016;91(2):191-8.
22. Green LA, Jones SM, Fetter G. Preparing the personal physician for practice: changing family medicine residency training to enable new model practice. Acad Med. 2007:82:1220-7.

23. Rossaro L, Tran TP, Ransibrahmanakul K, et al. Videoconferencing: the impact on continuing medical education for rural healthcare providers. Telemed J E Health. 2007;13(3):269-77.

24. Wolters R, Wensing M, Klomp M, Lagro-Jansen T, Cv W, Grol R. Effects of distance learning on clinical management of LUTS in primary care: a randomised trial. Patient Educ Couns. 2005;59(2):212-8.

25. Curran VR, Fleet L. A review of evaluation outcomes of web-based continuing medical education. Med Educ. 2005;39(6):561-7.

26. Converso D, Loera B, Viotti S, Martini M. Do positive relations with patients play a protective role for healthcare employees? Effects of patients' gratitude and support on nurses' burnout. Front Psychol. 2015;6:470.

27. Deveugele M. Communication training: skills and beyond. Patient Educ Couns. 2015;98(10):1287-91.

28. Raper SE, Gupta M, Okusanya O, Morris JB. Improving communication skills: a course for academic medical center surgery residents and faculty. J Surg Educ. 2015;72(6):e202-11.

29. National Health Commission of the People's Republic of China [Internet]. "Instructional advice on the job-transfer training of general practitioner in primary health care institution" by National Ministry of Health of China [in Chinese]; 2011. Available from: http://www.moh.gov.cn/zwgk/wtwj/201304/ 17900a13dacd466a89baaa1cc2b3fd4c.shtml. Accessed 11 Jan 2011.

\section{Ready to submit your research? Choose BMC and benefit from:}

- fast, convenient online submission

- thorough peer review by experienced researchers in your field

- rapid publication on acceptance

- support for research data, including large and complex data types

- gold Open Access which fosters wider collaboration and increased citations

- maximum visibility for your research: over $100 \mathrm{M}$ website views per year

At BMC, research is always in progress.

Learn more biomedcentral.com/submissions 